Review Article

\title{
A comparative analysis of NFHS-4 and 5 household profile indicators in districts of Haryana, India
}

\author{
Sunny Ohlan ${ }^{1}$, Sandeep Singh ${ }^{1}$, Parul Singhal $^{1 *}$, Rakhi Goyal$^{2}$, Antim Goyal ${ }^{3}$
}

\begin{abstract}
${ }^{1}$ Department of Community Medicine, SHKM Government Medical College, Nalhar, Haryana, India
${ }^{2}$ Department of Anesthesia, AL-Flah School of Medical Science and Research Centre, Faridabad, Haryana, India

${ }^{3}$ Department of Physiotherapy (Orthopedics), Gurugram University, Haryana, India
\end{abstract}

Received: 23 January 2022

Accepted: 15 February 2022

\section{*Correspondence:}

Dr. Parul Singhal,

E-mail: parulsinghal $281 @$ gmail.com

Copyright: (C) the author(s), publisher and licensee Medip Academy. This is an open-access article distributed under the terms of the Creative Commons Attribution Non-Commercial License, which permits unrestricted non-commercial use, distribution, and reproduction in any medium, provided the original work is properly cited.

\begin{abstract}
National family health survey is a large scale, multi-round survey conducted in a representative sample of households throughout India. Till date there are five rounds of the NFHS surveys were conducted starting from NFHS-1 in 199293 followed by NFHS-2 in 1998-99 after that NFHS-3 in 2005-06, then NFHS-4 in 2015-16 and lastly and recently conducted NFHS-5 from 2019 to 2021. NFHS - 5 has been captured during 2019-20 and has been conducted in around 6.1 lakh households. The international institute for population sciences Mumbai, served as the nodal organization providing coordination and technical guidance for the NFHS. In order to monitor the ongoing health and family welfare programs in between two census, NFHS is being undertaken. Household's profile indicators of NFHS4 and 5 in this article comprised of improved sanitation facility, improved drinking water source, using iodized salt, coverage under a health insurance, a household with electricity and using clean fuel for cooking. The comparison will help in understanding where the policy and program makers need to be more focused as per administrative division of the state and area of household profile, in collaboration with National health programs and policies.
\end{abstract}

Keywords: Cooking fuel, Drinking water, Sanitation, Health insurance, NFHS

\section{INTRODUCTION}

India is the second-most populous country in the world after China. As per the 2011 census of India, there were approximately 19.26 crore households. ${ }^{1}$ The main sources of demographic and Health-related indicators in India are census, sample registration system (SRS) and national family health survey (NFHS). The decennial Census of India was conducted 15 times till 2011, while it has been undertaken every 10 years, beginning in 1872 . The first census was done in $1881 .^{2}$ Census is conducted once in a decade so in due course of time for monitoring health indicators in the country SRS and NFHS are being conducted. SRS is a dual record system wherein a resident part-time enumerator (usually a teacher or Anganwadi worker) continuously records births and deaths in each household within the sample unit every month. The National family health survey (NFHS) is done on a large-scale, conducted in a representative sample of households throughout India and it is a multidimensional approach. Each successive round of the NFHS has had two specific goals: to provide essential data on health and family welfare needed by the Ministry of health and family welfare and other agencies for policy and programme purposes, and to provide information on important emerging health and family welfare issues. ${ }^{3}$ NFHS-5 (2019-21) has adopted a modular approach to arrive at estimates of crucial indicators at the State /UT level and a subset of these indicators at the district level. In the household profile of NFHS areas included are improved sanitation facility, improved drinking water source, using iodized salt, coverage under a health insurance/ financing scheme, a household with electricity and using clean fuel for cooking. Haryana with 22 
districts, is a state in the northern region of India harboring a population of 2,53 crore as per 2011 census. 4 In this article six household indicators enumerated in NFHS 5 are analyzed and compared with NFHS 4 in all districts of Haryana to understand the trends and impact of policies and programs on household profiles directly linked to health. This may help in redirecting the future health policies and health-related programs for researchers or scholars to rethink and implement things in the right direction \& efficient use of resources of the State.

\section{Households that use an improved sanitation facility.}

An improved sanitation facility is defined as one that hygienically separates human excreta from human contact. It is not necessarily identical to sustainable sanitation. ${ }^{5}$

According to WHO, an improved sanitation facility is one that likely hygienically separates human excreta from human contact. Improved sanitation facilities include: flush or pour-flush to the piped sewer system, septic tank or pit latrine, ventilated improved pit latrine, pit latrine with slab and cmposting toilet, however, sanitation facilities are not considered improved when shared with other households, or open to public use. In contrast "unimproved sanitation facility" is a public or shared latrine (meaning a toilet that is used by more than one household) flush/pour-flush to elsewhere (not into a pit, septic tank, or sewer) pit latrine without a slab. (WHO \& UNICEF, 2010). ${ }^{6}$ In 2020, 68\% of the world population had access to improved sanitation facilities. This means almost one-third of people do not have access. ${ }^{1}$ As per NFHS 5 (Table 1). In Haryana every district house-holds which are using an improved sanitation facility are more than 75 percent except one district (Mewat).

Eight districts are in the range of more than $85 \%$ coverage in NFHS-5 data and three districts have more than or equal to $90 \%$ coverage. Mewat district shows maximum growth rate i.e.; $21 \%$ in coverage of improved sanitation facility in NFHS-5 as compared to NFHS-4 and two more districts survey data added i.e., Charkhi-Dadri and Bhiwani in NFHS-5 as data was not previously present in NFHS-4 from 2015-2016 and both districts have coverage approximately to ninety percent. Six districts of Haryana show a decline are Karnal, Fatehabad, Ambala, Kurukshetra, Panipat and Panchkula in coverage of improved Sanitation facilities in NFHS-5 as compared to NFHS-4 data (Table 1). A novel campaign started by the Haryana state government in 2005 with walls of villages of Haryana have a painted message: "I won't allow my daughter to marry into a home without toilets." The social marketing campaign urging parents of brides to demand toilets at marriage negotiations has led to a dramatic increase of $21 \%$ in private sanitation coverage in Haryana, particularly in rural areas. This campaign encouraged families with marriageable girls to demand the construction of a toilet in the prospective groom's family as a precondition to marriage. ${ }^{5}$

The "no toilet, no bride" initiative linked social norms around the marriage market and access to sanitation. Since the start of SBM (Swatch Bharat Mission) in 2014, urban areas of 23 states/UTs have become ODF, and more than $94 \%$ of cities are already ODF. June was indeed a Swachh month for the government as rural areas of Haryana and Nearly 63 lakh individual household toilets (94\% progress), and more than 5 lakh community / public toilet seats (more than $100 \%$ progress) have been constructed. Parallelly, more than 42,000 public toilet blocks across 1400 cities have been mapped and visible on Google maps. ${ }^{6}$ Also, in the Swachh Survekshan Gramin-2019, the Haryana State has achieved 2nd rank in the Country and top in North India in Swachh Survekshan Gramin 2019 conducted by the Government of India. District Faridabad and Rewari have achieved 2nd and 3rd rank respectively in the country.

\section{Households with an improved drinking water source Households classified by source of drinking water according to Census of India}

Water provides the base for the existence of humans on Earth. An improved drinking-water source is defined as a type of water source that, by nature of its construction or through active intervention, is likely to be protected from outside contamination, in particular from contamination with faecal matter. ${ }^{8}$ According to joint monitoring program (JMP), an unimproved drinking-water source is one that by the nature of its construction does not adequately protect the source from outside contamination, in particular with faecal matter. Unimproved drinkingwater sources includes Unprotected (dug) well; unprotected spring, cart with small tank or drum; tanker truck-provided water, surface water (river, dam, lake, pond, stream, canal, irrigation channel); bottled water (because of potential limits on the quantity of water available to a household through this source, not the quality).

In Haryana, every district household which is using an improved drinking water source coverage is more than 95 percent according to recently released district fact sheets of NFHS-5 of Haryana state from 2019 to 2021. If we look at the two districts which were not previously present in NFHS-4 that are Charkhi-Dadri and Bhiwani both the newly added districts in NFHS-5 have coverage of $97 \%$. The district Yamunanagar has the maximum coverage i.e., $100 \%$ in both NFHS-4 and 5 (Table 1). Indicator 6.1 .1 of SDG 6 is "proportion of population using safely managed drinking water services". The term "safely managed drinking water services" is defined as: "drinking water from an improved water source that is located on-premises, available when needed and free from faecal and priority chemical contamination". 9 Haryana has become the third state in the country to provide access to clean drinking water to every rural 
household under the Jal Jeevan Mission after Goa and Telangana. According to census 2011, total households in Haryana were 2931429 and as per survey of PHED Haryana households are 3033306. Under jal jeevan mission (JJM), 18,12,693 (59.8\%) households have been provided functional household tap connection (FHTC). Households with FHTC before JJM were 1188609. The remaining households without FHTC are $32064(1.1 \%){ }^{10}$

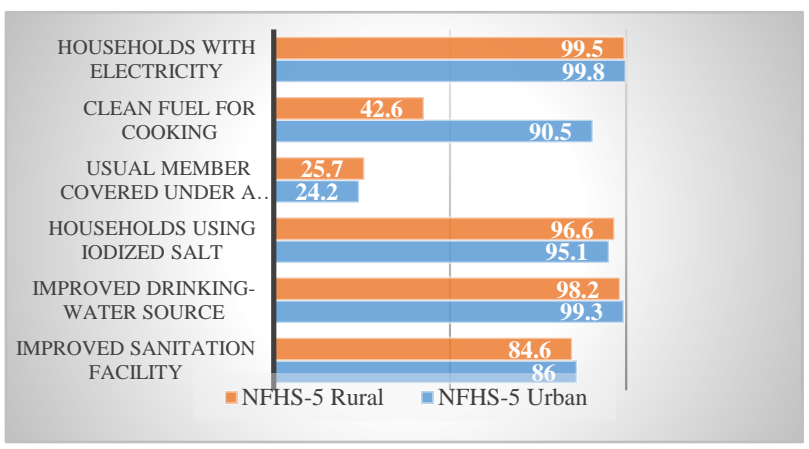

Figure 1: Comparison of urban-rural household profile indicators in Haryana (NFHS-5).

\section{Households using iodized salt}

Worldwide, iodine deficiency affects about two billion people and is the leading preventable cause of intellectual and developmental disabilities. ${ }^{11}$ Iodised salt was introduced to India in the late 1950s. Public awareness was increased by special programs and initiatives, both governmental and nongovernmental. In 2009 survey found that $9 \%$ of households used non-iodized salt and that another $20 \%$ used insufficiently iodized salt. ${ }^{12}$

Table 1 depicts that, according to recently released district fact sheets of NFHS-5 of Haryana state from 2019 to 2021, every district in Haryana households which using iodized salt coverage shows more than 90 percent and the two districts Bhiwani and Charkhi-Dadri in NFHS-5 have coverage of approximately $95 \%$. The district which shows highest inflation in coverage of households using iodized salt in NFHS-5 as compared to NFHS-4 is Mewat (25.9\%) followed by Palwal (12.3\%). A global nutrition organisation in collaboration with the All-India Institute of Medical Sciences, New Delhi had conducted a country-wide study 'India iodine survey 2018-19' to estimate the iodine status of the population and assess the extent to which Indian households have access to adequately iodised salt. A total of 55 percent of those surveyed had heard about iodised salt and 61.4 percent mentioned prevention of goitre as the primary benefit of consuming iodised salt. Awareness about iodised salt was 62.2 percent in urban areas and 50.5 percent in rural areas. $^{13}$

\section{Health insurance/financing scheme}

Universal health coverage means that all people have access to the health services they need, when and where they need them, without financial hardship. It includes the full range of essential health services, from health promotion to prevention, treatment, rehabilitation, and palliative care. ${ }^{14}$ According to WHO and the World Bank, half the world still lacks access to essential health services. ${ }^{15}$ About 60 million Indians fall into poverty annually due to expenditure on health. Out of pocket spending by families currently comprises over $60 \%$ of health care expenditure in India. This is the highest among the G20 countries. ${ }^{16}$ It has also been documented that expenditure on medicine constitutes about $70 \%$ of the total out-of-pocket expenditure in India. ${ }^{17,18}$ PM-JAY is a flagship scheme of GOI, launched in 2018 as recommended by the National health policy 2017, to achieve the universal health coverage (UHC). And to meet sustainable development goals (SDGs) It covers up to 3 days of pre-hospitalization and 15 days posthospitalization expenses such as diagnostics and medicines.16 Even though only $38.7 \%$ population is covered under Health Insurance according to recently released NFHS. ${ }^{5}$

In Haryana households with any usual member covered under a health insurance that are reported in NFHS 5 were $25.7 \%$ which doubles than the previous NFHS data. As shown in (Table 2), Maximum and minimum percentage of households with any member covered under a health insurance was observed in Faridabad and Nuh district with coverage of $34 \%$ and $11 \%$ respectively. If we see the trends of NFHS $4 \& 5$, health financing schemes of all districts reflected an increase in the coverage. District Fathehabad with highest raise (26.3\%) in coverage of health insurance scheme and Ambala was found to have least $(2.3 \%)$ raised coverage while Panchkula, Kurukshetra and Ambala districts were having less than $20 \%$ coverage. Charkhi-dadri and Bhiwani districts in NFHS-5 are newly added having coverage above $25 \%$. Under PM-JAY Percentage of families covered were $33 \%$ as of November $2021 .^{19}$

\section{Clean fuel for cooking in households}

Clean fuel there is defined by the emission rate targets and specific fuel recommendations (i.e. against unprocessed coal and kerosene) included in the normative guidance WHO guidelines for indoor air quality. Clean fuel is one component of sustainable energy. ${ }^{20}$ As per the global burden of disease study 2019, nearly 600,000 deaths in India in 2019 can be attributed to indoor air pollution. Burning of solid fuels to prepare food on simple cook stoves (chulha) in homes exposes families, particularly women and children, to the harmful impacts of smoke and indoor air pollution (IAP)..$^{21}$ During 2010 to 2016, India provided electricity to 30 million people each year, more than any other country, the World Bank said in its latest report released in March 2018. ${ }^{22}$

According to census 2011, households having electricity were $90.5 \%$ which has increased to $99.6 \%$ in NFHS-5. Around $81 \%$ households were having clean fuel for 
cooking in Districts of Ambala, Gurugram and Panchkula. The percentage of household having clean cooking fuel reported in Haryana in NFHS 5 is around $60 \%$ with a marked Urban Rural difference with $90 \%$ \& $40 \%$ respectively (Figure 2). Faridabad was having highest percentage $(89 \%)$ of household with clean cooking fuel whereas least percentage of household with clean cooking fuel was seen in Nuh (11\%). The proportion of households using clean cooking fuel was declined in Gurugram and Sirsa district where as it was raised in rest of districts. Bhiwani and Charkhi-dadri in NFHS-5 has $36 \%$ households using clean cooking fuel. Highest growth in the households with clean cooking fuel was seen in Rohtak and Sonipat district (21.5\%) (Table 2).

Table 1: Districts fact sheet of population living in households improved sanitation facility, improved drinking water and using iodized salt.

\begin{tabular}{|c|c|c|c|c|c|c|c|c|c|}
\hline \multirow{2}{*}{$\begin{array}{l}\text { State and } \\
\text { districts }\end{array}$} & \multicolumn{3}{|c|}{ Improved Sanitation facility } & \multicolumn{3}{|c|}{$\begin{array}{l}\text { Improved drinking water } \\
\text { source }\end{array}$} & \multicolumn{3}{|c|}{ Households using Iodized salt } \\
\hline & $\begin{array}{l}\text { NFHS } \\
5\end{array}$ & $\begin{array}{l}\text { NFHS } \\
4\end{array}$ & Inference & $\begin{array}{l}\text { NFHS } \\
5\end{array}$ & $\begin{array}{l}\text { NFHS } \\
4\end{array}$ & Inference & $\begin{array}{l}\text { NFHS } \\
5\end{array}$ & $\begin{array}{l}\text { NFHS } \\
4\end{array}$ & Inference \\
\hline Haryana & 85 & 80.6 & Increased & 98.6 & 98.3 & Increased & 96.1 & 92.9 & Increased \\
\hline Ambala & 87.2 & 90.9 & Decreased & 99.3 & 99.8 & Decreased & 96.2 & 96 & Increased \\
\hline Bhiwani & 89.7 & N/A & - & 97.5 & N/A & - & 94.5 & N/A & - \\
\hline Charkhi Dadri & 90.4 & N/A & - & 97.3 & N/A & - & 95.5 & N/A & - \\
\hline Faridabad & 84.2 & 80.5 & Increased & 97.9 & 99.2 & Decreased & 95.4 & 91.8 & Increased \\
\hline Fatehabad & 87.3 & 88.7 & Decreased & 99.8 & 99.9 & Decreased & 94.3 & 96.7 & Decreased \\
\hline Gurgaon & 84.5 & 70.9 & Increased & 99.7 & 99.5 & Increased & 97.6 & 94.8 & Increased \\
\hline Hisar & 89.1 & 86.3 & Increased & 99.3 & 96.2 & Increased & 95.8 & 91.4 & Increased \\
\hline Jhajjar & 91.7 & 87.7 & Increased & 96.6 & 98.8 & Decreased & 96.3 & 93.1 & Increased \\
\hline Jind & 88.5 & 85.4 & Increased & 96.2 & 92.1 & Increased & 95.9 & 94.6 & Increased \\
\hline Kaithal & 89.7 & 79.2 & Increased & 98.5 & 99.8 & Decreased & 97 & 89.6 & Increased \\
\hline Karnal & 83.5 & 88.5 & Decreased & 99.9 & 100 & Decreased & 97.8 & 94.4 & Increased \\
\hline Kurukshetra & 82.6 & 87.1 & Decreased & 99.9 & 100 & Decreased & 97.1 & 95.1 & Increased \\
\hline Mahendragarh & 79.8 & 74.9 & Increased & 99.7 & 99.5 & Increased & 97.4 & 89.9 & Increased \\
\hline Mewat & 71.7 & 50.6 & Increased & 97.1 & 94.2 & Increased & 93.4 & 67.5 & Increased \\
\hline Palwal & 80.3 & 68.4 & Increased & 96.7 & 95.4 & Increased & 95.3 & 83 & Increased \\
\hline Panchkula & 82.6 & 86 & Decreased & 99.2 & 99.6 & Decreased & 97.6 & 98.3 & Decreased \\
\hline Panipat & 79.3 & 91.7 & Decreased & 99.9 & 99.9 & Constant & 97.2 & 98.2 & Decreased \\
\hline Rewari & 86.4 & 72.6 & Increased & 99.7 & 99.4 & Increased & 97.7 & 97.1 & Increased \\
\hline Rohtak & 90 & 78.4 & Increased & 98.5 & 99.2 & Decreased & 95 & 98.6 & Decreased \\
\hline Sirsa & 81.9 & 81.1 & Increased & 99.3 & 99.7 & Decreased & 95.7 & 88.3 & Increased \\
\hline Sonipat & 86.7 & 82.5 & Increased & 97.2 & 99.7 & Decreased & 96.6 & 97.8 & Decreased \\
\hline Yamunanagar & 83.5 & 81.3 & Increased & 100 & 100 & Constant & 94.4 & 96.7 & Decreased \\
\hline
\end{tabular}

'Pradhan Mantri Ujjwala Yojana' (PMUY) as a flagship scheme with an objective to make clean cooking fuel such as LPG available to the rural and deprived households which were otherwise using traditional cooking fuels such as firewood, coal, cow-dung cakes etc.

Usage of traditional cooking fuels had detrimental impacts on the health of rural women as well as on the environment. $^{23}$

Total 89,582,788 connections released under Pradhan Mantri Ujjwala yojana as on 28th December 2021 and 9,630,735 Connections released under Ujjwala 2.0 as on 28th Dec 2021. ${ }^{23}$

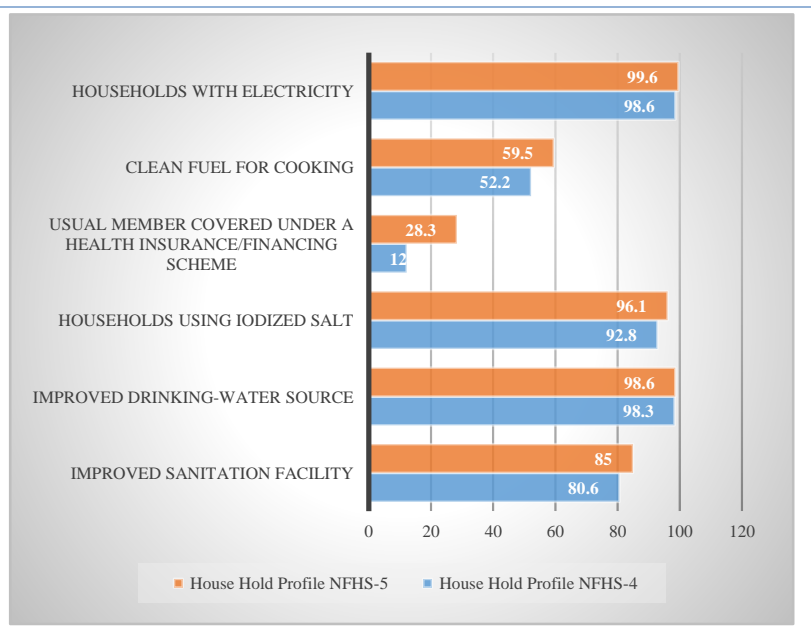

Figure 2: Comparison of NFHS 5 and 4 household profile indicators in Haryana. 


\section{Households with electricity}

In Haryana, (Table 2) depicts that almost $100 \%$ household were reported having households with electricity. This much percentage of household with electricity supply gives hope for using electricity as a source for replacement of LPG as a clean cooking fuel. Decreased trend for households with electricity has been shown in districts of Gurugram, Karnal, Kurukshetra,
Panchkula, Panipat, Sonipat and Yamunanagar. Nuh and Palwal districts were having a growth of $8.6 \%$ and $4.5 \%$ respectively in households with electricity. To facilitate the consumers, the LED (bulbs, tube lights) and energy efficient fans under Prime Minister's Unnat Jyoti by Affordable LEDs for All (UJALA) programme has been launched since 2015. In Haryana 1.56 crore LED bulbs has been distributed till date. ${ }^{24}$

Table 2: Districts fact sheet of population living in households with any member covered under health insurance scheme, using clean cooking fuel and electricity.

\begin{tabular}{|c|c|c|c|c|c|c|c|c|c|}
\hline \multirow{2}{*}{$\begin{array}{l}\text { State and } \\
\text { districts }\end{array}$} & \multicolumn{3}{|c|}{$\begin{array}{l}\text { Health insurance/financing } \\
\text { scheme }\end{array}$} & \multicolumn{3}{|c|}{ Clean fuel } & \multicolumn{3}{|c|}{ Electricity } \\
\hline & NFHS 5 & NFHS 4 & Inference & NFHS 5 & $\begin{array}{l}\text { NFHS } \\
4\end{array}$ & Inference & NFHS 5 & NFHS 4 & Inference \\
\hline Haryana & 25.7 & 12.2 & Increased & 59.5 & 52.2 & Increased & 99.6 & 98.9 & Increased \\
\hline Ambala & 19.0 & 16.7 & Increased & 81.6 & 67.8 & Increased & 99.6 & 99.9 & Decreased \\
\hline Bhiwani & 28.2 & - & - & 36.6 & - & - & 100.0 & - & - \\
\hline Charkhi Dadri & 29.7 & - & - & 36.2 & - & - & 99.5 & - & - \\
\hline Faridabad & 32.8 & 18.8 & Increased & 89.3 & 82.6 & Increased & 100.0 & 99.3 & Increased \\
\hline Fatehabad & 29.4 & 3.1 & Increased & 43.7 & 39.1 & Increased & 99.8 & 99.8 & Constant \\
\hline Gurgaon & 34.6 & 18.4 & Increased & 81.0 & 82.0 & Decreased & 99.4 & 99.8 & Decreased \\
\hline Hisar & 27.9 & 10.3 & Increased & 44.8 & 38.8 & Increased & 99.7 & 99.2 & Increased \\
\hline Jhajjar & 27.0 & 13.4 & Increased & 55.9 & 43.9 & Increased & 99.8 & 99.3 & Increased \\
\hline Jind & 23.7 & 9.5 & Increased & 42.1 & 36.8 & Increased & 100.0 & 99.5 & Increased \\
\hline Kaithal & 29.1 & 13.9 & Increased & 55.9 & 41.1 & Increased & 100.0 & 99.9 & Increased \\
\hline Karnal & 24.6 & 11.4 & Increased & 74.1 & 54.7 & Increased & 99.2 & 99.8 & Decreased \\
\hline Kurukshetra & 19.2 & 8.1 & Increased & 77.6 & 59.1 & Increased & 99.6 & 99.9 & Decreased \\
\hline Mahendragarh & 25.6 & 10.4 & Increased & 34.2 & 32.9 & Increased & 99.6 & 98.8 & Increased \\
\hline Mewat & 11.5 & 7.9 & Increased & 22.0 & 17.2 & Increased & 98.6 & 90.0 & Increased \\
\hline Palwal & 23.5 & 10.5 & Increased & 34.6 & 30.6 & Increased & 98.9 & 94.4 & Increased \\
\hline Panchkula & 19.9 & 11.9 & Increased & 81.1 & 77.3 & Increased & 99.5 & 99.7 & Decreased \\
\hline Panipat & 26.5 & 9.5 & Increased & 73.0 & 63.6 & Increased & 99.6 & 100.0 & Decreased \\
\hline Rewari & 25.3 & 18.1 & Increased & 54.9 & 39.1 & Increased & 100.0 & 99.0 & Increased \\
\hline Rohtak & 24.8 & 9.9 & Increased & 67.3 & 45.8 & Increased & 99.7 & 99.4 & Increased \\
\hline Sirsa & 26.6 & 8.4 & Increased & 38.8 & 41.8 & Decreased & 99.9 & 99.3 & Increased \\
\hline Sonipat & 22.4 & 9.4 & Increased & 69.9 & 48.4 & Increased & 99.3 & 99.6 & Decreased \\
\hline Yamunanagar & 20.6 & 11.0 & Increased & 77.7 & 61.6 & Increased & 99.8 & 99.9 & Decreased \\
\hline
\end{tabular}

India's move to energize every village in the country with electricity is one of the greatest success stories in the world in 2018. Saubhagya- Pradhan mantri sahaj bijli har ghar yojana is India's effort towards achieving $100 \%$ village electrification, Government of India also focused in achieving electrification of all un-electrified households in the country. one of the world's biggest Universal electrification initiative with collaborative and concerted efforts of Centre and States. It is a concurrent program to Deen Dayal Upadhyaya gram jyoti yojana' (DDUGJY). ${ }^{25}$

In (Figure 2), all the household profile indicators have increased in NFHS 5 as compared to NFHS 4 in Haryana.

There is not much urban rural difference in household profile indicators except clean cooking fuel (Figure 1).

\section{CONCLUSION}

The key challenge of India is to provide access to safe drinking water and improved sanitary conditions for the increasing population. Improved sanitation facilities households and percentage with clean fuel for cooking have increased in almost all the 22 districts over the last four years from 2015-16 to 2019-21. Micronutrient deficiencies are now recognized as an important contributor to the global burden of disease. Level of iodine in the diet in the form of salt is largely recommended as universal salt iodization (USI) is recommended under National iodine deficiency disorders control programme (NIDDCP) to address the wide spectrum of iodine deficiency disorders (IDDs) such as goitre, cretinism, dwarfism, still-births, abortions and mental retardation. In rural area, there should be more emphasis on clean cooking fuel. Other aspects like using 
clean fuel will reduce the burden of COPD and pulmonary diseases and morbidity \& mortality due to indoor air pollution. In 21 st century, electricity is the basic need of household. Electrification of all districts help in clean energy state will low emission of pollutants and will also excel the digital India Program to transform Haryana into a digitally empowered State and Society. The hours of electricity supply and solar electricity panel installation in household should be included in NFHS for data on use of renewable energy source. We have to be focused more than as compared to other indicators on Health Insurance to reduce the out of pocket expenditure or to tackle Natural and Man-Made disasters, so that in any crisis or emergency it may help people living in the community. Out of pocket payments which is acknowledged to impoverish individuals and households and push household to below poverty line. In this sense, Health Insurance coverage will not just encourage the equal treatment for the equals (horizontal equity) but allows for unequal treatment to un-equals (vertical equity) $\&$ preventing discrimination in access to health services, eradicating stigma and increasing social protection for marginalized and vulnerable groups. Even after PM-JAY the health coverage is not achieved up to the mark, and needs strengthening of PM-JAY and AYUSHMAN Bharat through operational research. The scope of expansion of PM-JAY to cover large population of country should be considered viewing the unorganized work sector of country such as agriculture. In this way we are also reducing the burden of major public health problems by performing better as compared to earlier in the improved sanitation, improved drinking water, using iodized salt, using clean fuel for cooking, coverage under a health insurance scheme and households with electricity. But still, more is to be done to achieve and sustain the indicators.

\section{Funding: No funding sources Conflict of interest: None declared \\ Ethical approval: Not required}

\section{REFERENCES}

1. Census India. Available at: https://censusindia. gov.in/tables_published. Accessed on 29 December 2021.

2. Where-are-indias-census-figures-on religion. Available at: www.https://blogs.wsj.com/indiareal time. Accessed on 29 December 2021.

3. National Family Health Survey - 5. 2021. Available at: http://rchiips.org/nfhs/India.pdf. Accessed on 29 December 2021.

4. Size, growth rate and distribution of population, Ranking of States and Union Territories by population: 2001 and 2011. Available at: www.https://census india.gov.in. Accessed on 29 December 2021.

5. Water supply monitoring programme. Available at: www.https://joint monitoring programme for water supply and sanitation - wikimili, the best wikipedia reader. Accessed on 29 December 2021.

6. Population using improved sanitation facilities (\%) (who.int). Available at: https://www.who.int/data/ gho/data/indicators/indicator-details/GHO. Accessed on 19 December 2021.

7. Swachh-Bharat-Mission-gramin. Available at: http://haryanadp.gov.in/SCHEMES. Accessed on 29 December 2021.

8. WHO and UNICEF definitions of improved drinkingwater source on the JMP website Archived 2012-0606 at the Wayback Machine, WHO, Geneva and UNICEF, New York. Available at: https://www.bing.com/newtabredir?url=https $\% 3 \mathrm{~A} \% 2$ F\%2Fwww.who.int $\% 2 F w a t e r$ sanitation_health\%2F monitoring\%2Fjmp2012\%2Fkey terms $\% 2 \mathrm{Fen} \% 2 \mathrm{~F}$. Accessed on 20 December 2021.

9. Progress on drinking water, sanitation and hygiene. Available at: https://www. data.unicef.org/ resources/progress-drinking-water-sanitation-hygiene. Accessed on 20 December 2021.

10. PHED-Dashboard, Government of Haryana. Available at: https://phedharyana.gov.in/PHED-Dashboard/ Index.html. Accessed on 28 December 2021.

11. Sankar R. Iodine deficiency-way to go yet. Lancet. 2010;372(9633):88.

12. Rah JH, Anas AM, Chakrabarty A, Sankar R, Pandav CS, Aguayo VM. Towards universal salt iodisation in India: achievements, challenges and future actions. Matern Child Nutr. 2015;11(4):483-96.

13. Indian households consume adequately iodised salt, finds a survey. Available at: https://fit.thequint. com/chew-on-this/ 76\%. Accessed on 28 December 2021.

14. WHO Fact Sheet-Universal Health Coverage. WHO. Assessed at: https://www.who.int/health-topics/ universal-health-coverage\#tab=tab_1. Accessed on 28 December 2021.

15. Universal Health Coverage out-reach-unless-weeliminate-discrimination?. United nations development Project. Available at: https://www. undp.org/blog/universal-health-coverage-out-reachunless-we-eliminate-discrimination?utm_source=EN \&utm_medium=GSR\&utm_content=US_UNDP_Paid Search_Brand_English\&utm_campaign $=$ CENTRAL\& c_src=CENTRAL\&c_src2 $=$ GSR \&gclid $=$ Cj0KCQiA8 ICOBhDmARIsAEGI6o1E6gNcw405XmY4pd3MUh 95uDrNzfb5hc57INA9Ge5eyXSTcKfZpuYaAnb0EA Lw_wcB. Accessed on 28 December 2021.

16. PMJAY-About. Available at: https://pmjay.gov.in/ node/1685. Accessed on 28 December 2021.

17. Garg C, Karan AK. Reducing out-of-pocket expenditures to reduce poverty: a disaggregated analysis at rural-urban and state level in India. Health Policy Plan. 2008;24(2):116-28.

18. Gupta I, Joe W. Refining estimates of catastrophic healthcare expenditure: an application in the Indian context. Int J Health Care Finance Econ. 2012;13(2): 157-72. 
19. Haryana-PMJAY-Profile. PMJAY.GOI. Available at: https://pmjay.gov.in/haryana-profile/PDF. Accessed on 28 December 2021.

20. WHO indoor air quality guidelines: household fuel combustion. Available at: https://www.who.int/ airpollution/guidelines/household-fuelcombustion/en/. Accessed on 28 December 2021.

21. Agrawal S, Mani S, Jain A, Ganesan K, Urpelainen J. India Residential Energy Survey (IRES) 2020. Available at: https://www.pceew.in/india-residentialenergy-survey. Accessed on 28 December 2021.

22. Jha, Lalit K. India doing extremely well on electrification: World Bank Mint. Available at: https://www.rstv.nic.in/india-extremely-wellelectrification-world-bank.htm. Accessed on 28 December 2021.
23. Pradhan Mantri Ujjwala Yojana. Available at: https://www.pmuy.gov.in/about. Accessed on 28 December 2021.

24. Ujala Dashboard Ministry of Power, Government of India. Unnat Jyoti by Affordable LEDs for all. Available at: http://ujala.gov.in/state-dashboard/ haryana. Accessed on 28 December 2021.

25. Ministry of Power, Government of India. SAUBHAGYA- Pradhan Mantri Sahaj Bijli Har Ghar Yojana. Available at: https://powermin.gov.in/en/ content/saubhagya. Accessed on 28 December 2021.

Cite this article as: Ohlan $\mathrm{S}$, Singh $\mathrm{S}$, Singhal $\mathrm{P}$, Goyal R, Goyal A. A comparative analysis of NFHS4 and 5 household profile indicators in districts of Haryana, India. Int J Community Med Public Health 2022;9:1556-2. 